\section{Engineering just-so stories}

Invention by Design: How Engineers get from Thought to Thing

by Henry Petroski

Harvard University Press: 1996. Pp. 242.

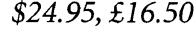

\section{David Jones}

The keypad of a telephone has the digits 1,2,3 at the top. That of a calculator has the digits $7,8,9$ in this position. Most of us use both of design?

This is one of the questions left as an exercise for the reader by Henry Petroski in his survey of the design history of a selection of familiar objects. He starts small, with paperclips, pencils, zip fasteners, beverage cans and fax machines, and finishes big, with aircraft, water distribution systems, bridges and buildings. His themes are the Darwinian, evolutionary nature of the engineering design process and the slow, often irregular optimization of its artefacts. The book is a series of stories about how his chosen products came to be the way they are.

His vision, like that of all good Darwinians, is optimistic. Bad designs fail in the market-place while good ones thrive, so technology steadily improves. Here is the 'chemisealed' pencil of 1930, with its graphite centre bonded to its wooden surround. It thus forms a superior cantilever beam, less likely to break at the tip. Here is the aluminium beverage can, in its triumphant progress towards ever-lower weight, easier opening and (with the invention of the retained opening tab) more efficient recycling. Here is the fax machine, its steady improvement driven appropriately by the Japanese, whose ideographic script is almost impossible to send by teleprinter.

The technical aspects of these stories are devices every day. How serious is this failure very appealing. To see a pencil as a cantilever beam or a beverage can as a pressure vessel is to feel the power of engineering insight. The commercial aspects also have their subtlety. In the long history of the paper-clip, innumerable patents were taken out on various designs, and almost all of them failed. The now-universal 'Gem' clip, which dates from about 1890, was never patented. Its most successful exponent, William Middlebrook of Connecticut, patented instead a machine for making it. It could churn out Gem clips so cheaply that they came to dominate the market.

But beneath the technicalities, engineering design is a social activity. Its consistent problem is the conveying of facts and ideas from one mind to another. Even the oldstyle inventor in his garret or garage faces this problem. He may do all the thinking, designing and constructing himself, but he still has to sell his vision to his backers. If he succeeds, his vision will reach the marketplace, where his customers may (or may not) accept it as well.

Modern engineering, especially that of large systems such as bridges and aircraft, is beyond any single inventor. It needs teams of designers. The difficulties of exchanging ideas within a team are serious: they might be expected to rise as the square of the number of members.

The traditional solution is that of hierarchy. Nevil Shute in No Highway (1948) paints a striking portrait of the ferocious aircraft designer E. P. Prendergast, “...a man of immensely powerful will, capable of imposing his idea and his way of doing things on each of a hundred draughtsmen, so that each one of them is too terrified to insert any of his own ideas".

Prendergast was based on the great
Barnes Wallis. His dogmatic approach contrasts strongly with Petroski's exposition of the democratic, computerized system used by Boeing half a century later to design the 777 aircraft. Designs and drawings for the whole craft were stored in eight of IBM's largest mainframe computers, and each of thousands of designers could call down any drawing to his workstation. If two drawings conflicted, the clash was immediately apparent. Petroski does not say if the conflicts were settled by democratic vote or authoritarian diktat.

But the Boeing model is still highly unusual. One traditional mental divide is still very much with us: that between designers and engineers. The designers dream up a component or even a complete product; they then (as Petroski puts it) "throw it over the wall" to the wretched engineers, who have to figure out some way of making it. If the engineers succeed in making the thing, and the sales force in selling it widely, the designers will soon be back at work on a new model - usually without even bothering to discover what was wrong with the old one.

Some manufacturers, it is said, deliberately rush a flawed product to market, and allow the resulting customer complaints to guide the design of its replacement. But even this rudimentary feedback is often ignored. The most crucial mental gulf of all, and the most seldom bridged, is that between designers and users. I would have welcomed more discussion of this problem; its neglect or misunderstandingleads to numerous bad designs.

In the electronic age, the deadliest temptation for the designer is to add more features. Petroski's account of the fax machine is one of steady improvement, standardization, and simplification. Yet many electronically controlled goods - such as video cassette recorders, washing machines and photocopiers - are almost unusably complicated.

Pride of place in the dysfunctional design stakes must go to computer software. The most amazing achievement of the computer software industry is its continuing cancellation of the steady and staggering gains made by the computer hardware industry. Analysts look in vain for any serious increase in overall productivity from the vast global investment in computers over the past 20 years. Let us hope that, even now, Darwin is grooming some unsuspected software mutation for the mighty and much-needed kill.

As for the problem of the incompatible keypads, it cannot be long before somebody makes a telephone with calculator attachment, or possibly a calculator with telephone attachment. We should then at least discover which of the numeric arrangements is more fitted to survive.

David Jones is in the Chemistry Department at the University of Newcastle, Newcastle upon Tyne NE1 7RU, UK. 